Article

\title{
Soil Thermal Balance Analysis for a Ground Source Heat Pump System in a Hot-Summer and Cold-Winter Region
}

\author{
Zhongchao Zhao *, Rendong Shen ${ }^{(}$, Weixian Feng, Yong Zhang and Yanrui Zhang \\ School of Energy and Power, Jiangsu University of Science and Technology, Zhenjiang 212003, Jiangsu, China; \\ shenrendong@163.com (R.S.); FWXzhenjiang@163.com (W.F.); 18896658850@163.com (Y.Z.); \\ zyr1056187930@163.com (Y.Z.) \\ * Correspondence: zhongchaozhao@just.edu.cn; Tel.: +86-0511-84493050
}

Received: 8 April 2018; Accepted: 2 May 2018; Published: 9 May 2018

\begin{abstract}
As a renewable and high energy efficiency technology providing air conditioning and domestic hot water, the ground source heat pump system (GSHPS) has been extensively used worldwide in recent years. Compared with conventional systems, GSHPSs with heat recovery reject less heat into the soil and extract more heat from it, which can help reduce soil thermal imbalance in hot-summer and cold-winter regions. In this paper, conventional GSHPS, and GSHPS with different heat recovery ratios, in a typical city were compared based on thermal imbalance ratios, average soil temperatures and soil temperature increases. The transient system simulation software was used to simulate the operation performance of GSHPS. The thermal imbalance ratio and soil temperature decreased with increasing heat recovery ratio. After 20 years of operation, the soil thermal imbalance ratios of the GSHPS were $29.2 \%, 21.1 \%, 16 \%$, and $5.2 \%$, and the soil temperature rises were $8.78{ }^{\circ} \mathrm{C}$, $5.25^{\circ} \mathrm{C}, 3.44{ }^{\circ} \mathrm{C}$, and $0.34{ }^{\circ} \mathrm{C}$, while the heat recovery ratios were $0,18 \%, 30 \%$ and $53 \%$, respectively. Consequently, a GSHPS with heat recovery is a potentially efficient and economical approach for buildings in hot-summer and cold-winter regions.
\end{abstract}

Keywords: soil thermal balance; ground source heat pump; average soil temperature; heat recovery

\section{Introduction}

Air conditioning and domestic hot water consume considerable energy that is predicted to increase quickly because of the rapid increase in building areas and high requirements of the ambient environment [1-3]. As the most extensively used heating system in China, coal boilers are of low energy efficiency, and contribute significantly to air pollution [4]. Due to air pollution creating smog conditions, clean heating technologies are in great demand [5]. As the most promising high energy efficiency technology for building heating and cooling, Ground Source Heat Pump systems (GSHPSs) have been extensively applied for air-conditioning and heating in buildings, due to their energy savings and emission reductions [6]. Taking the soil as the heat source or heat sink, they are always superior to air-source heat pump systems in efficiency. Typified by high efficiency and low pollution, GSHPSs have attracted great attention $[7,8]$.

However, for many buildings in hot-summer and cold-winter regions, heat extracted from the soil is not equal to the rejected heat in heating-dominated or cooling-dominated areas [9]. The thermal imbalance between heat injection and extraction to/from the ground causes heat accumulation in cooling-dominated buildings, and cold accumulation in heating-dominated buildings. Heat accumulation is common in hot-summer and cold-winter regions; soil temperature gradually increases after long-term operation since the temperature recovery is limited, which finally causes the deterioration of the cooling performance of the GSHPS [10]. 
Some approaches have been used to relieve this thermal imbalance: (1) Increasing the number, spacing and depth of drilling [11]. Increasing the number or spacing of boreholes increases the initial investment and occupied area. Moreover, neither the spacing of boreholes nor their number can fundamentally eliminate thermal imbalance; (2) Installing assisted heat sources. Solar collectors and heat supply networks are generally applied for the peak load, while the GSHPS only provides part of the heating load to keep the soil temperature balanced [12]; (3) Applying thermal energy storage. The storage battery as a thermal energy storage device integrated into the GSHPS for domestic hot water or distributed heating in buildings can decrease the heat extracted from soil in winter to maintain soil thermal balance [13].

Nguyen [14] and Rad [15] have reported the advantages of GSHPSs with boiler or solar energy used in cold regions. In recent years, the equipment selection, applicability, and operation control strategies of GSHPSs have been highlighted [16,17].

Yang et al. [18] reported an experiment and numerical research of a solar-assisted GSHPS in Nanjing of China. Solar energy was employed as a supplementary heat source to supply heat during daytime, and ground heat exchangers supplied heat during night, which reduced the heat extracted from the soil. What is more, different operation modes such as solar energy for heating during the daytime, and excess solar energy stored in the ground for heating at night, were also compared in this paper. The ground temperature could remain stable with the assistance of the solar collector, which benefited the coefficient of performance (COP) of the heat pump.

You et al. [19] investigated a ground-coupled heat pump integrated within an air-source heat compensator (AHC), which is called AHC-GCHP. AHC could operate directly to heat the water used for heat compensation in the soil when the surrounding air temperature was high. In addition, it could work together with the GCHP unit to provide heat compensation or domestic hot water, and even for space heating. More heat was extracted efficiently from air instead of soil by means of AHC, while the surrounding air temperature is high enough so as to effectively eliminate the soil thermal imbalance.

Although researchers have been devoted to circumventing soil thermal imbalance, only experimental methods or theoretical analyses are available at present. In contrast, numerical simulation for the soil thermal imbalance of GSHPSs for long operation durations remain scarce. Schibuola et al. [20] have established a warning system to solve this problem. During the process, the soil temperature standard curve was used as an early warning indicator, taking into account influential factors such as meteorological conditions, building loads, intermittent or continuous operation and the configuration of the GSHPS. Moreover, the standard time-temperature curves of three different weather conditions and the range of soil temperature were given, depending on the operation period.

Through calculation using energy consumption software, Liu [21] simulated the annual dynamic load in five typical climatic zones. The thermal imbalance ratios of five cities were calculated. Accordingly, the applicability of the GSHPS was analyzed. Shanghai, which is a hot-summer and cold-winter area, was most suitable to the use of GSHPSs.

Many approaches have been employed to solve the thermal imbalance problems of GSHPSs. GSHPSs integrated with solar energy storage or cooling tower have already been extensively used in several regions, but the performance of GSHPSs with heat recovery in hot-summer and cold-winter regions remains largely unknown.

In summary, the thermal imbalance problem is inescapable due to heat accumulation after long-term operation. In this research, the long-term operation performance of GSHPSs with heat recovery was simulated and compared with that of conventional GSHPSs, in terms of soil temperature variation, thermal imbalance ratio, and soil temperature rise. The findings contribute to the maintenance of soil thermal balance for GSHPSs with heat recovery.

\section{Methodology}

The dynamic heating and cooling loading of a Shanghai hotel was calculated on the basis of different meteorological and envelope thermal characteristic parameters. Shanghai is located 
in the hot-summer and cold-winter region of China, which belongs to the subtropical monsoon climate. The coldest and hottest weather of Shanghai occurs in January and August, with average temperatures of $4.7^{\circ} \mathrm{C}$ and $28.6^{\circ} \mathrm{C}$ respectively. The parameters for solar irradiation, wind speeds, and air humidity are listed in Table 1. The Transient System Simulation Program (TRNSYS) (16.0, UW-Madison, Madison, WI, USA) was selected to simulate the operation performance of a GSHPS with heat recovery. Soil temperatures, inlet/outlet temperatures of buried pipes, thermal imbalance ratios, and soil temperature rises of conventional GSHPSs and GSHPSs with heat recovery were obtained.

Table 1. Meteorological parameters for Shanghai region.

\begin{tabular}{ccc}
\hline Items & Monthly Average Value (June-September) & Monthly Average Value (December-February) \\
\hline Total solar irradiation $\left(\mathrm{W} / \mathrm{m}^{2}\right)$ & 175.6 & 102.7 \\
wind speeds $(\mathrm{m} / \mathrm{s})$ & 3.1 & 2.7 \\
air humidity $(\%)$ & 79 & 74 \\
\hline
\end{tabular}

\subsection{Dynamic Heating and Cooling Loadings Simulation of the Hotel Building}

A hotel building in the hot-summer and cold-winter area, which has a total floor area of $1130 \mathrm{~m}^{2}$ and a usable air-conditioning of $880 \mathrm{~m}^{2}$, was chosen as the study. There are 40 guest rooms in this hotel, which can accommodate 60 people at an occupancy rate of $75 \%$. The heat transfer coefficients of windows, whose total area is $60 \mathrm{~m}^{2}$, and of exterior walls and roofs, are $2.9 \mathrm{~W} /\left(\mathrm{m}^{2} \cdot \mathrm{K}\right), 0.65 \mathrm{~W} /\left(\mathrm{m}^{2} \cdot \mathrm{K}\right)$ and $0.52 \mathrm{~W} /\left(\mathrm{m}^{2} \cdot \mathrm{K}\right)$, respectively. The ventilation rate of each guest room in the hotel is $30 \mathrm{~m}^{3} /(\mathrm{h} \cdot \mathrm{p})$, and the internal heat loads including electrical equipment as well as lights are $20 \mathrm{~W} / \mathrm{m}^{2}$ and $15 \mathrm{~W} / \mathrm{m}^{2}$, respectively. Dynamic energy consumption of the GSHPS was simulated based on the hourly loadings of this hotel building. The calculation model mainly included a meteorological parameter module and a loading calculation module. A diagrammatic sketch of the dynamic loading calculation of the building is presented in Figure 1.

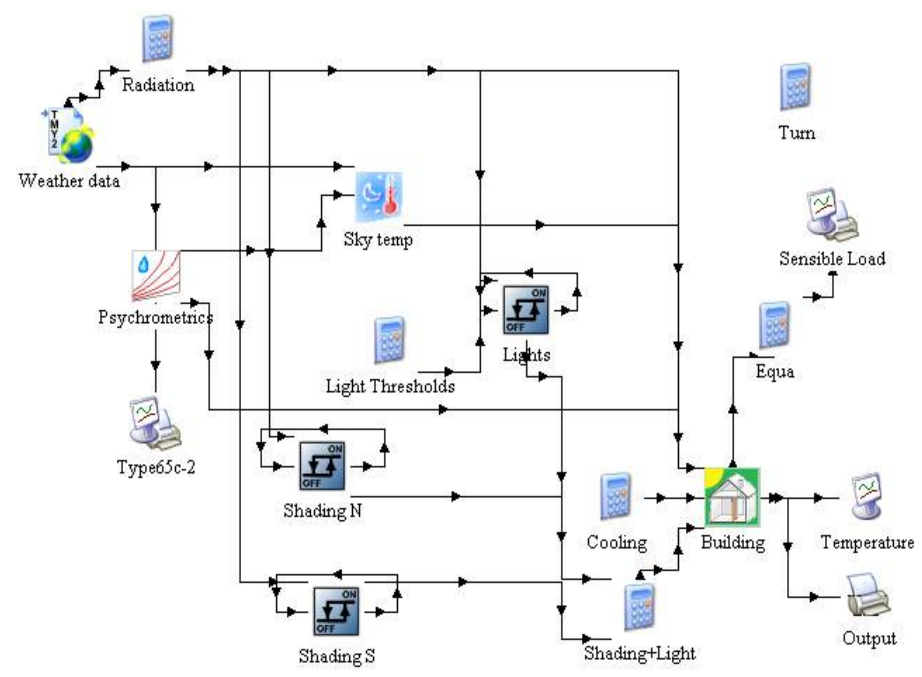

Figure 1. Calculation of annual dynamic cooling and heating hourly loadings.

\subsection{Ground Source Heat Pump System (GSHPS) Simulation Calculation Model}

The main difference between GSHPSs with heat recovery and conventional GSHPSs is in the design of the heat recovery system. For conventional GSHPSs in a Hot-Summer and Cold-Winter Region, the annual cold load is usually far higher than the heating load. The design standard of the ground heat exchanger in conventional GSHPSs is determined according to cold loads in summer, which will lead to heat accumulation. In this way, the accumulation of unbalanced heat will exceed the thermal diffusion ability of soil, so that soil temperature gradually increases. Compared with 
conventional GSHPSs, installing heat recovery devices to provide domestic hot water, GSHPSs with heat recovery decrease the heat rejected into ground in summer, while increasing the heating load in winter respectively, to keep the balance of the cold and heating load. Aiming at comparing the difference of soil thermal imbalance between them, the heat recovery GSHPS simulation model, mainly including a heat pump module and an underground vertical buried pipe exchanger module, was established by TRNSYS 16.0. As shown in Figure 2, the conventional GSHPS can be adjusted by opening the diverting valve and control signal of the heat pump. An operation flow chart of the heat recovery for the GSHPS is presented in Figure 3.

Aiming at comprehensively demonstrating the soil thermal imbalance of GSHPSs with heat recovery, four scenarios were analyzed based on the dynamic simulation method. The parameters for all the scenarios, including borehole number, heat recovery ratios, and information about the ground heat exchanger are listed in Table 2. The calculation principles are presented as follows.

(1) Cooling season:

Heat rejected into the soil in summer:

$$
Q_{\text {rejected }}=\text { Cap }_{\text {cooling }}+P_{\text {cooling }}
$$

where Cap cooling - heat removed from the indoor environment $(\mathrm{kW})$ and $P_{\text {cooling }}$-work consumed by the heat pump $(\mathrm{kW})$.

Outlet temperatures of circulating liquid in source side and loading side:

$$
\begin{gathered}
T_{\text {source }, \text { out }}=T_{\text {source, in }}+\frac{Q_{\text {rejected }}}{m_{\text {source }} C p_{\text {source }}} \\
T_{\text {load }, \text { out }}=T_{\text {load, in }}-\frac{\text { Cap } p_{\text {cooling }}}{m_{\text {load }} C p_{\text {load }}}
\end{gathered}
$$

where,

$T_{\text {source, } \text { in }}$-Inlet temperature of circulating liquid in heat pump source side, ${ }^{\circ} \mathrm{C}$;

$m_{\text {source }}$-Mass flow rate of circulating liquid in heat pump source side, $\mathrm{kg} / \mathrm{h}$;

$C p_{\text {source }}$-Specific heat of circulating liquid in heat pump source side, $\mathrm{kJ} /(\mathrm{kg} \cdot \mathrm{K})$;

$T_{\text {load, } i n}$-Inlet temperature of circulating liquid in heat pump loading side, ;

$m_{\text {load }}$-Mass flow rate of circulating liquid in heat pump loading side, $\mathrm{kg} / \mathrm{h}$;

$C p_{\text {load }}$-Specific heat of circulating liquid in heat pump loading side, $\mathrm{kJ} /(\mathrm{kg} \cdot \mathrm{K})$.

(2) Heating season:

Heat absorbed from the soil in winter:

$$
Q_{\text {absorbed }}=\text { Capheating }_{\text {heating }}
$$

where Capheating represents the heating supplied to the indoor environment $(\mathrm{kW}), P_{\text {heating }}$ is the work consumed by the heat pump $(\mathrm{kW})$.

Outlet temperature of circulating liquid in source side and loading side:

$$
\begin{gathered}
T_{\text {source,out }}=T_{\text {source, in }}-\frac{Q_{\text {absorbed }}}{m_{\text {source }} C p_{\text {source }}} \\
T_{\text {load }, \text { out }}=T_{\text {load, in }}+\frac{\text { Cap } p_{\text {heating }}}{m_{\text {load }} C p_{\text {load }}}
\end{gathered}
$$


Table 2. Parameters for all scenarios.

\begin{tabular}{ccccc}
\hline \multirow{2}{*}{ Item } & Conventional GSHPS & \multicolumn{2}{c}{ Heat Recovery GSHPS } \\
\cline { 2 - 5 } & Case 1 & Case 2 & Case 3 & Case 4 \\
\hline Borehole number & 38 & 31 & 27 & 17 \\
Heat recovery ratio & 0 & $18 \%$ & $30 \%$ & $53 \%$ \\
Buried pipe length & $3800 \mathrm{~m}$ & $3100 \mathrm{~m}$ & $2700 \mathrm{~m}$ & $1700 \mathrm{~m}$ \\
Borehole depth & & $100 \mathrm{~m}$ & \\
Geometry of the ground heat exchanger & \multicolumn{4}{c}{ Vertical U-Tube } \\
\hline
\end{tabular}

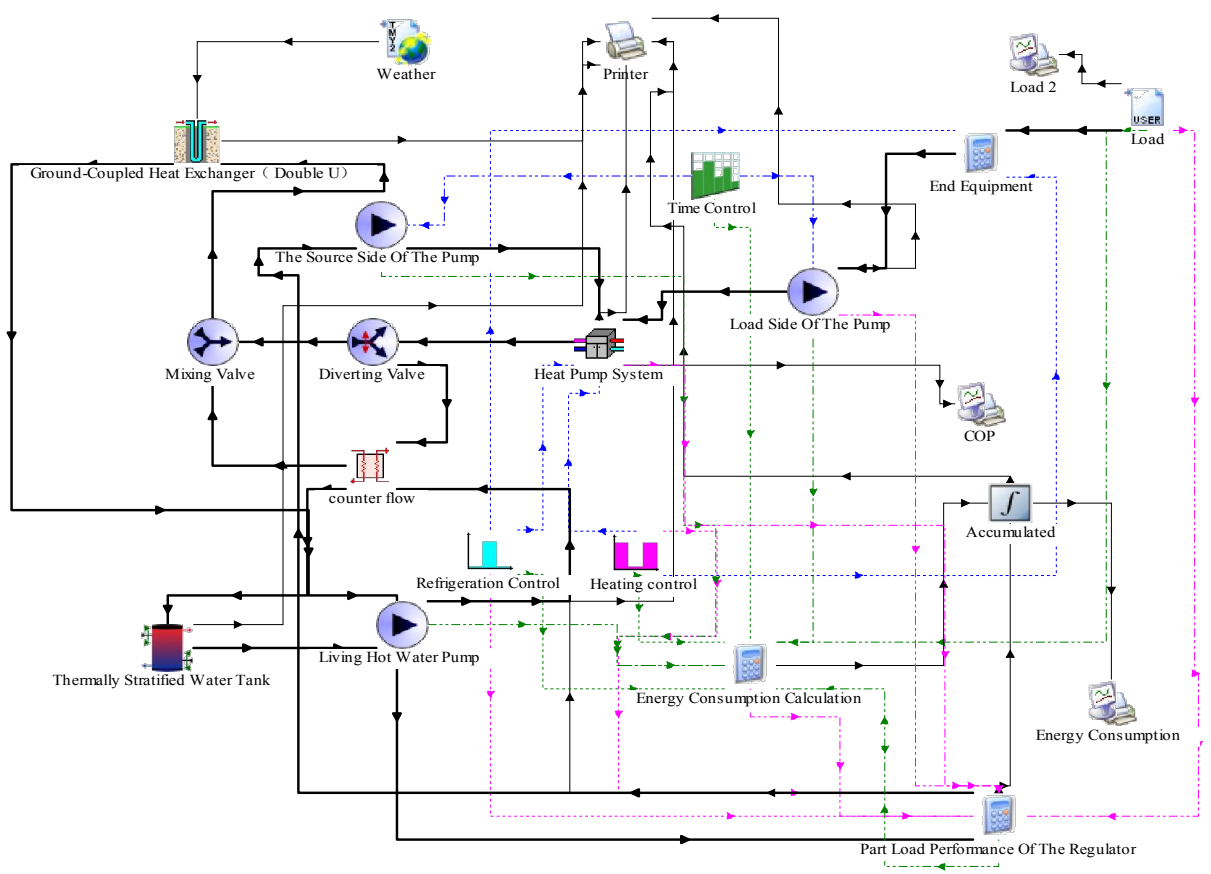

Figure 2. Model of the hybrid ground source heat pump system (GSHPS).

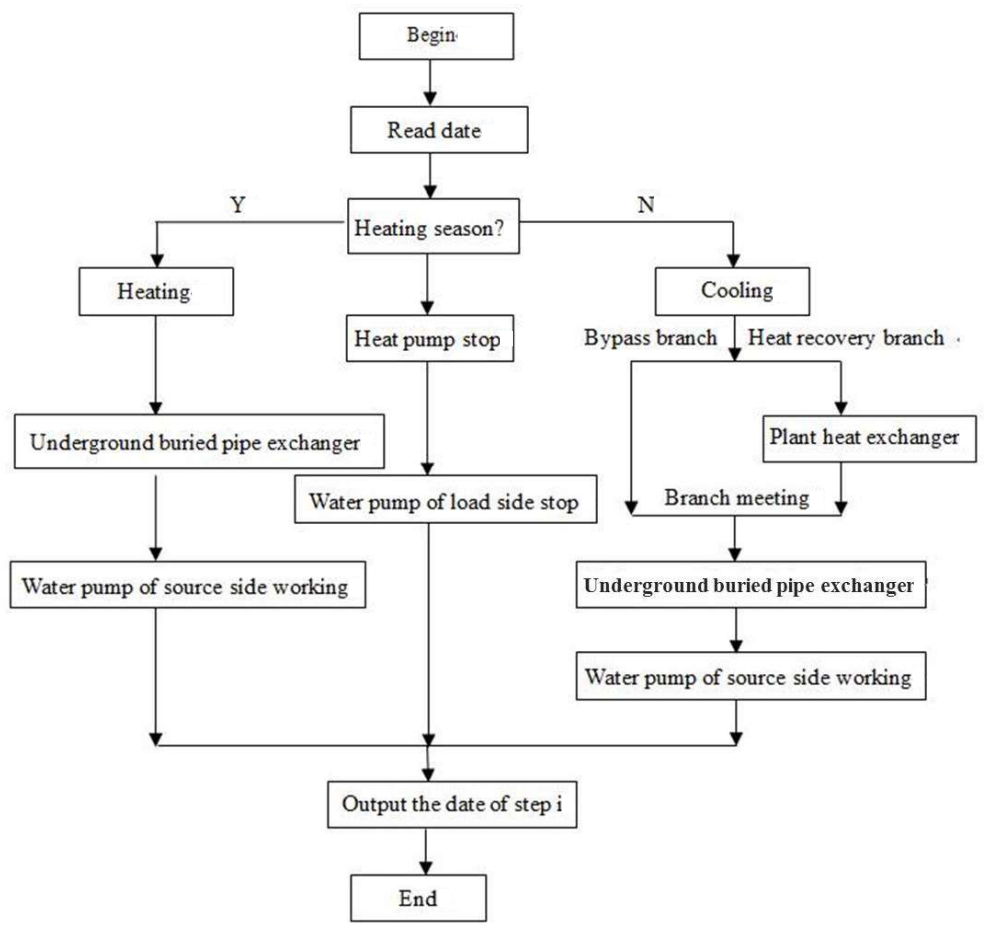

Figure 3. Operation flow chart of the hybrid GSHPS. 


\subsection{Evaluation Method}

\subsubsection{Thermal Imbalance Ratio}

Thermal imbalance ratio, which is determined by the heat extracted from the soil in winter and that rejected into the soil in summer, can be obtained from studying the building load and heat pump performance.

The accumulated heating load and cooling load are defined as:

$$
\begin{gathered}
Q_{A H L}=\sum_{\text {heating,s }}^{8760} Q_{i}+\sum_{1}^{\text {heating,e }} Q_{i} \\
Q_{A C L}=\sum_{\text {cooling,s }}^{\text {cooling,e }} Q_{i}
\end{gathered}
$$

where,

$Q_{i}$ - hourly heating or cooling load, $\mathrm{kW}$;

Cooling, $s$ and cooling, $e-$ start and end times for cooling;

Heating, $s$ and heating, $e$ - start and end times for heating.

The accumulated heat extraction during heating and the accumulated heat rejection during cooling can be calculated as:

$$
\begin{gathered}
Q_{A H E}=\sum_{\text {heating, }}^{8760} Q_{i}\left(1-\frac{1}{C O P_{\text {heating }, i}}\right)+\sum_{1}^{\text {heating, },} Q_{i}\left(1-\frac{1}{\operatorname{COP}_{\text {heating }, i}}\right) \\
Q_{A H R}=\sum_{\text {cooling }, \mathrm{s}}^{\text {cooling }, e} Q_{i}\left(1+\frac{1}{\operatorname{COP}_{\text {cooling }, i}}\right)
\end{gathered}
$$

where $C O P_{\text {heating, }, i}$ and $C O P_{\text {cooling }, i}$ are the hourly heating $C O P$ and hourly cooling $C O P$ obtained from dynamic simulation, respectively.

Finally, the thermal imbalance ratio is defined as:

$$
\mathrm{IR}=\frac{Q_{A H R}-Q_{A H E}}{\max \left(Q_{A H R}, Q_{A H E}\right)} \times 100 \%
$$

IR is used to determine the thermal imbalance classification of GSHPS. A positive IR indicates that the heat rejected into the soil exceeds the extracted heat, which usually happens in hot-summer and cold-winter regions. A lower IR means a smaller difference between heating and cooling loads.

\subsubsection{Average Soil Temperature}

The difference between the heat extracted from soil in winter and that rejected into soil in summer can be estimated using thermal imbalance; average soil temperature is a basic index to directly estimate the effect of soil thermal imbalance. In order to simulate the soil temperature, the design heating load, design cooling load, and borehole number for the GSHPS should be chosen based on the building loads simulated previously.

\section{Results and Discussion}

\subsection{Calculation of Annual Dynamic Heating and Cooling Hourly Loadings}

Based on the calculation model, the annual dynamic heating and cooling hourly loadings of this hotel building in Shanghai were calculated, and the simulation results are shown in Figure 4. 


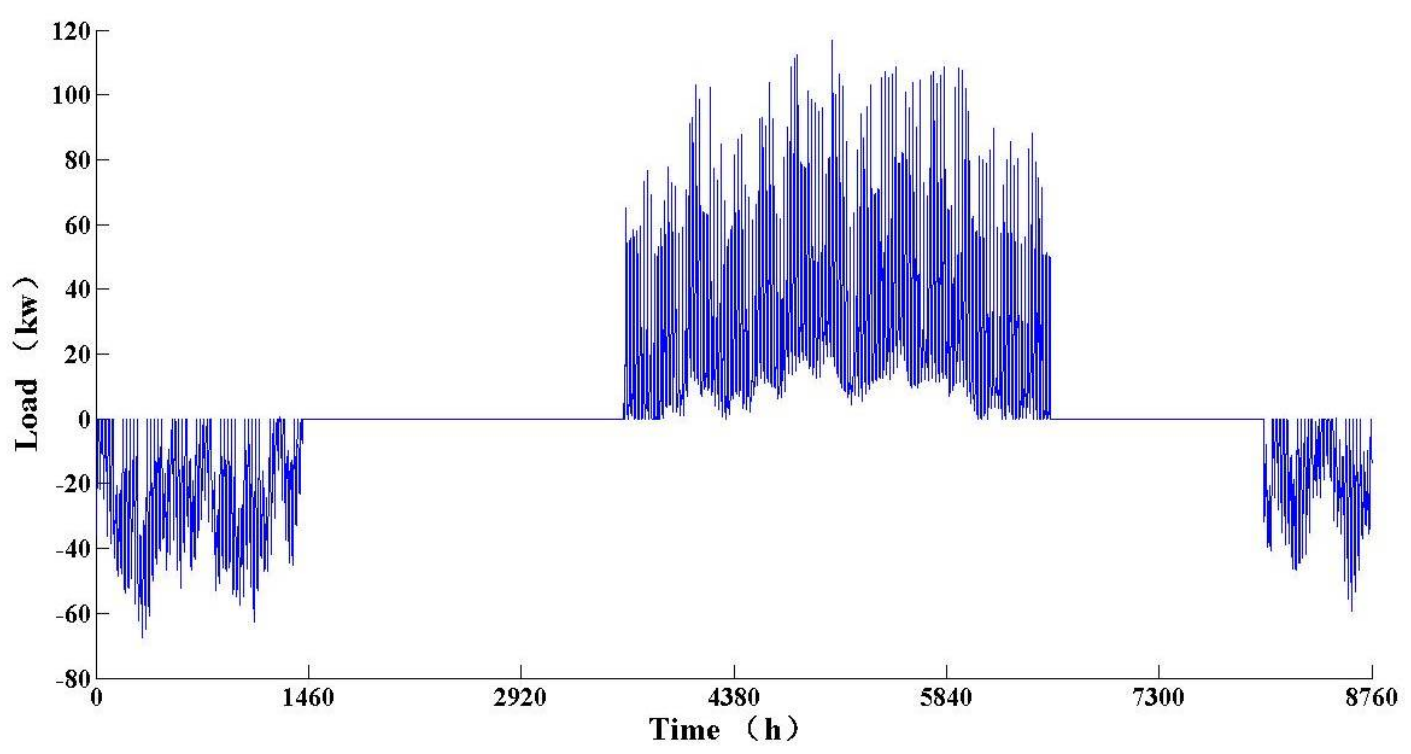

Figure 4. Annual dynamic cooling and heating hourly loads.

The peak heating load and cooling loading of this hotel building was $67.49 \mathrm{~kW}$ and $116.66 \mathrm{~kW}$ respectively. The heating period was from 15 December to 15 February, and the cooling period from 1 June to 1 September. Therefore, the total annual accumulative heating and cooling loadings were $192,884.3 \mathrm{kWh} / \mathrm{m}^{2}$ and $357,053.3 \mathrm{kWh} / \mathrm{m}^{2}$ respectively. According to the load characteristics of the hotel building's requirements, it is crucial to focus on the thermal balance problem during GSHPS design.

\subsection{Soil Thermal Balance}

Soil thermal balance is of great significance for the maintenance of efficient and stable operation of GSHPSs, the destruction of which changes the soil temperature, thereby seriously affecting the overall operation performance after several years of system operation. In order to compare the soil thermal balances of heat recovery GSHPSs and conventional GSHPSs, the transient simulation model was adopted.

The simulation results of dynamic thermal imbalance ratio over 20 years are presented in Table 3 .

Table 3. Calculated results of soil thermal imbalance ratio with 4 cases (\%).

\begin{tabular}{ccccccccccc}
\hline Year & $\mathbf{1}$ & $\mathbf{2}$ & $\mathbf{3}$ & $\mathbf{4}$ & $\mathbf{5}$ & $\mathbf{6}$ & $\mathbf{7}$ & $\mathbf{8}$ & $\mathbf{9}$ & $\mathbf{1 0}$ \\
\hline Case 1 & 44.3 & 39.5 & 36.7 & 34.9 & 33.7 & 32.8 & 32.2 & 31.7 & 31.3 & 30.9 \\
Case 2 & 35.6 & 30.2 & 27.3 & 25.7 & 24.7 & 23.9 & 23.4 & 23.0 & 22.7 & 22.4 \\
Case 3 & 28.1 & 23.0 & 20.5 & 19.2 & 18.4 & 17.9 & 17.5 & 17.2 & 17.0 & 16.8 \\
Case 4 & 8.0 & 6.5 & 5.7 & 5.3 & 5.2 & 5.1 & 5.0 & 5.0 & 5.0 & 5.0 \\
\hline Year & $\mathbf{1 1}$ & $\mathbf{1 2}$ & $\mathbf{1 3}$ & $\mathbf{1 4}$ & $\mathbf{1 5}$ & $\mathbf{1 6}$ & $\mathbf{1 7}$ & $\mathbf{1 8}$ & $\mathbf{1 9}$ & $\mathbf{2 0}$ \\
\hline Case 1 & 30.6 & 30.4 & 30.2 & 30.0 & 29.8 & 29.7 & 29.6 & 29.4 & 29.3 & 29.2 \\
Case 2 & 22.2 & 22.0 & 21.8 & 21.7 & 21.6 & 21.5 & 21.4 & 21.3 & 21.2 & 21.1 \\
Case 3 & 16.6 & 16.5 & 16.4 & 16.3 & 16.2 & 16.1 & 16.1 & 16.0 & 16.0 & 16.0 \\
Case 4 & 5.0 & 5.0 & 5.0 & 5.1 & 5.1 & 5.1 & 5.1 & 5.1 & 5.1 & 5.2 \\
\hline
\end{tabular}

The thermal imbalance ratio decreased slowly with system operation from case 1 to case 3 , while the imbalance rate of case 4 fluctuated slightly. The imbalance ratios from case 1 to case 4 , which were $44.3 \%, 35.6 \%, 28.1 \%$ and $8.0 \%$ after one-year of operation, reduced to $29.2 \%, 21.1 \%, 16.0 \%$ and $5.2 \%$ respectively after 20 years. Case 4 basically achieved thermal balance. 


\subsection{Average Soil Temperature}

Ground thermal imbalance has a significant effect on soil temperature, and will consequently affect the operation performance of heat pump. In order to investigate soil temperature variation after long-term operation, GSHPSs with different heat recovery ratios in hot-summer and cold-winter areas were dynamically simulated and compared with conventional GSHPSs. Figure 5 shows the hourly average soil temperatures in the first year of operation in Shanghai.

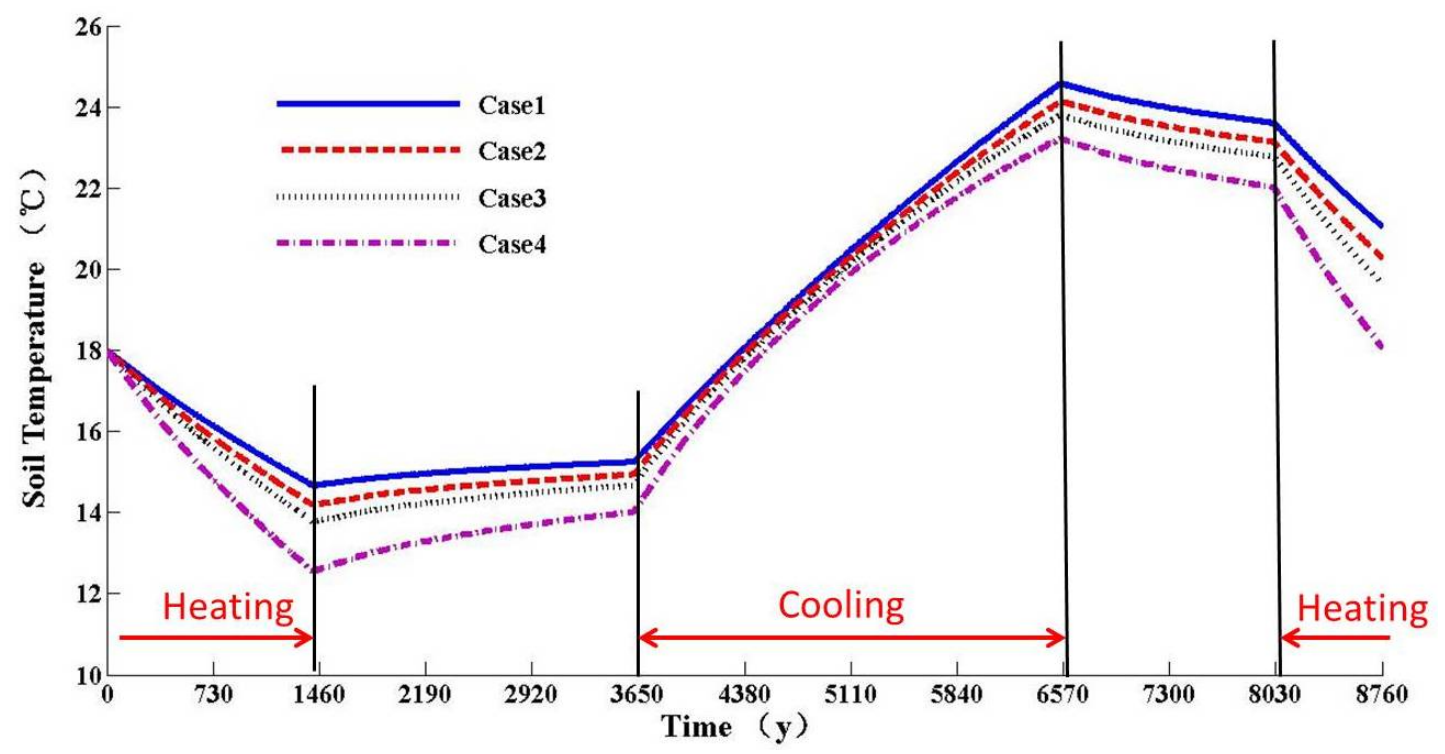

Figure 5. Average soil temperatures in the first year of operation.

The average soil temperature of GSHPSs decreased faster in the heating season and more slowly in the cooling season, with an increase in the heat recovery ratio. The four cases had similar levels of heat extracted from the soil in heating season. The heat transfer among soil and buried pipes was weakened with increasing heat recovery ratios and reducing buried pipe lengths. Therefore, the average soil temperature decreased with increasing heat recovery ratios. As a result, the temperatures across the four cases followed a descending order: case $1>$ case $2>$ case $3>$ case 4 .

In the cooling season, heat rejected into the soil decreased with increasing heat recovery ratios, so the soil temperatures changed like those in heating season. After the first year of operation, the average soil temperatures of the four cases rose by $16.9 \%, 12.6 \%, 9.1 \%$ and $0.3 \%$ to $21.05^{\circ} \mathrm{C}, 20.27^{\circ} \mathrm{C}$, $19.64{ }^{\circ} \mathrm{C}$ and $18.06{ }^{\circ} \mathrm{C}$ respectively. However, the increase of soil temperature was not linearly related to the recoverable heat, because of the heat recovery ability of the soil itself.

The yearly average soil temperatures of cases 1 and 4 in 20 years of operation are presented in Figure 6. They increase annually, but the temperature rise of case 1 evidently surpassed that of case 4 . For case 4 , the average soil temperature, at the same time every year, barely changed $\left(18-19^{\circ} \mathrm{C}\right)$ after 20 years. However, such temperatures as those of case 1 increased faster in the first 10 years of operation. In other words, the cooling performance in case 4 improved, while that for case 1 deteriorated. 


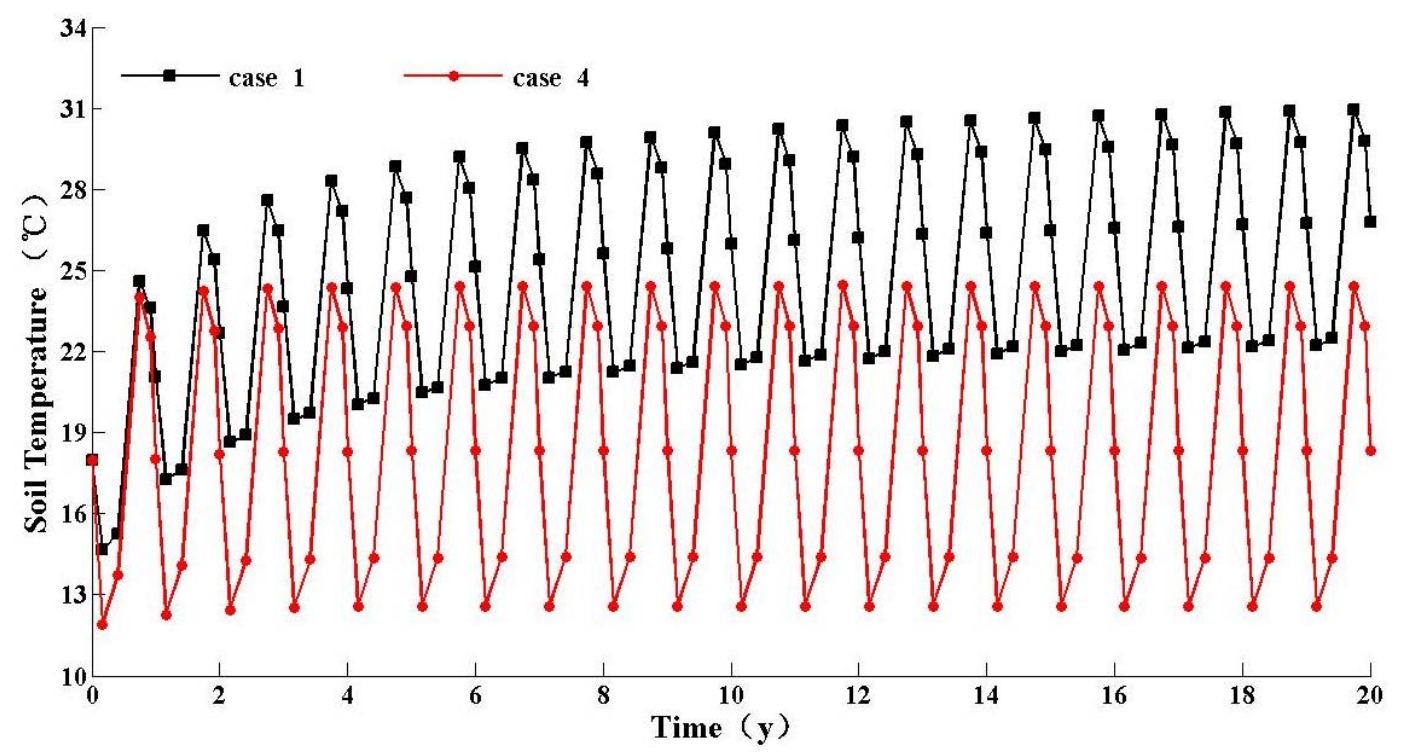

Figure 6. Average soil temperatures of 20 years of operation.

The highest average soil temperatures on 30 September, and the average soil temperatures on 31 December of the four cases each year, were analyzed and compared. The yearly average maximum temperatures of the soil are presented in Figure 7; average soil temperature variations of the four cases are shown in Figure 8.

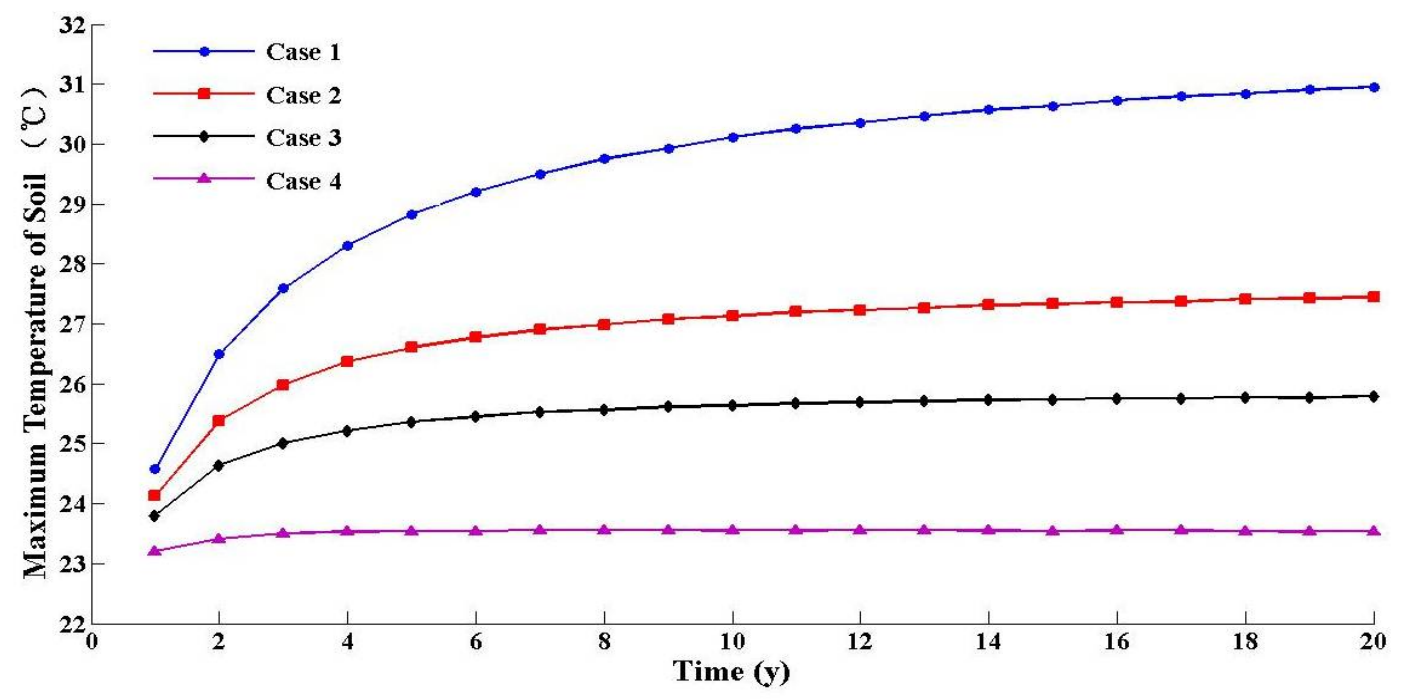

Figure 7. Yearly average maximum temperatures. 


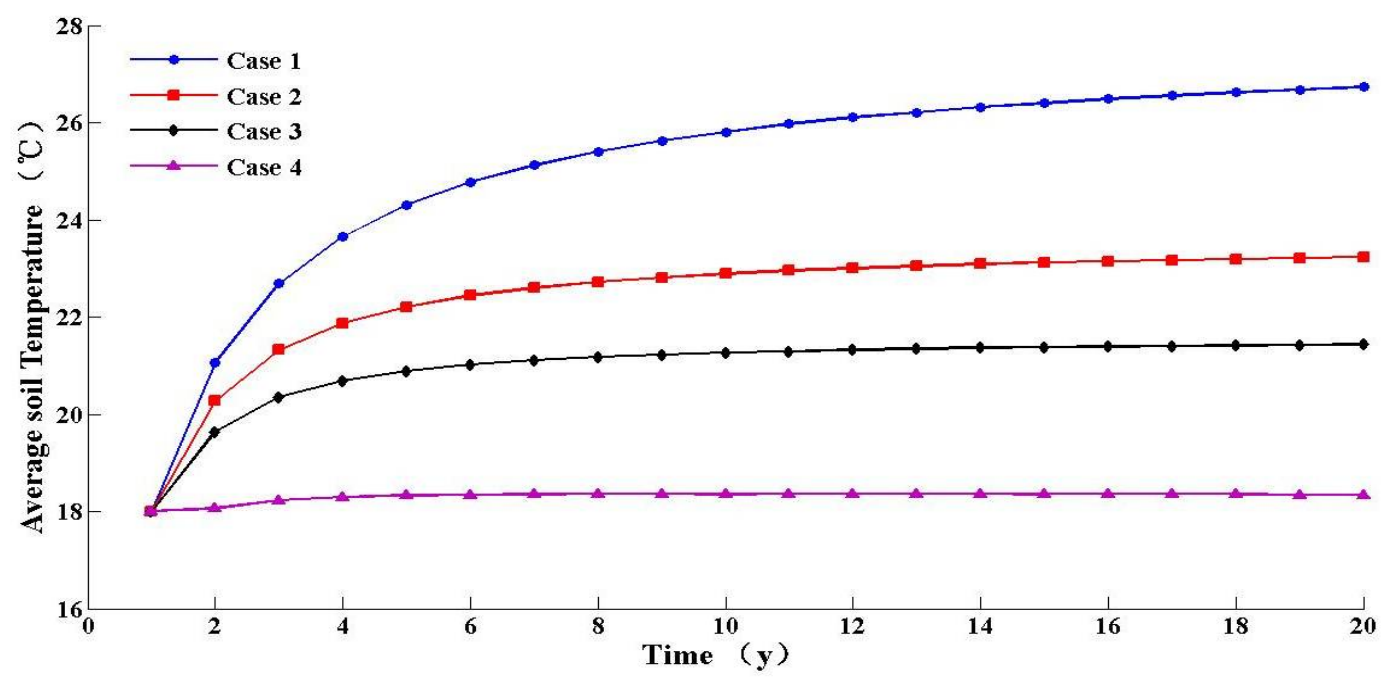

Figure 8. Average soil temperature variation of 4 scenarios at the same period.

With the operation of GSHPSs, the yearly maximum soil temperatures of the four cases slowly increased, albeit with significantly different ranges. The soil temperature of case 1 increased from $24.57^{\circ} \mathrm{C}$ to $30.94{ }^{\circ} \mathrm{C}$ after 20 years, and remained stable thereafter. However, for case 4 , the maximum soil temperature remained virtually the same, at $23.5^{\circ} \mathrm{C}$, over 20 years of operation. The highest average soil temperatures of cases 2,3 and 4 were $27.43^{\circ} \mathrm{C}, 25.78{ }^{\circ} \mathrm{C}$ and $23.52^{\circ} \mathrm{C}$, which were $3.51{ }^{\circ} \mathrm{C}$, $5.16^{\circ} \mathrm{C}$ and $7.42{ }^{\circ} \mathrm{C}$ lower than that of case 1 , respectively.

According to Table 4, the average soil temperatures rise more remarkably in the first and second years. The average soil temperatures in the second year from case 1 to case 4 were $1.63^{\circ} \mathrm{C}, 1.05^{\circ} \mathrm{C}$, $0.71{ }^{\circ} \mathrm{C}$ and $0.17^{\circ} \mathrm{C}$ higher than those in the first year, respectively. Nevertheless, such temperatures in the 20th year were $0.04{ }^{\circ} \mathrm{C}, 0.02{ }^{\circ} \mathrm{C}, 0.01{ }^{\circ} \mathrm{C}$ and $0{ }^{\circ} \mathrm{C}$ higher than those in the 19th year. As for GSHPSs with much greater heat rejection than heat extraction, the soil temperature increased significantly in the first few years, because heat rejected into the soil markedly exceeded the thermal diffusion ability itself. Although the accumulated heat rejection surpassed the accumulated heat extraction after long-term operations, the rise of soil temperatures decreased due to enhanced thermal diffusion.

Table 4. Soil temperature rises of 4 cases.

\begin{tabular}{|c|c|c|c|c|c|c|c|c|c|c|}
\hline $\begin{array}{c}\text { Temperature } \\
\text { Rise }\end{array}$ & $\Delta t_{1,2}$ & $\Delta t_{2,3}$ & $\Delta t_{3,4}$ & $\Delta t_{4,5}$ & $\Delta t_{5,6}$ & $\Delta t_{6,7}$ & $\Delta t_{7,8}$ & $\Delta t_{8,9}$ & $\Delta t_{9,10}$ & $\Delta t_{10,11}$ \\
\hline Case 1 & 1.63 & 0.97 & 0.65 & 0.47 & 0.35 & 0.28 & 0.23 & 0.18 & 0.16 & 0.14 \\
\hline Case 2 & 1.05 & 0.55 & 0.34 & 0.23 & 0.16 & 0.12 & 0.09 & 0.07 & 0.06 & 0.05 \\
\hline Case 3 & 0.71 & 0.34 & 0.20 & 0.13 & 0.09 & 0.07 & 0.05 & 0.04 & 0.03 & 0.03 \\
\hline Case 4 & 0.17 & 0.07 & 0.03 & 0.01 & 0.01 & 0.01 & 0.01 & -0.01 & 0 & 0 \\
\hline $\begin{array}{l}\text { Temperature } \\
\text { Rise }\end{array}$ & $\Delta t_{11,12}$ & $\Delta t_{12,13}$ & $\Delta t_{13,14}$ & $\Delta t_{14,15}$ & $\Delta t_{15,16}$ & $\Delta t_{16,17}$ & $\Delta t_{17,18}$ & $\Delta t_{18,19}$ & $\Delta t_{19,20}$ & $\Delta t_{1,20}$ \\
\hline Case 1 & 0.11 & 0.10 & 0.08 & 0.08 & 0.08 & 0.06 & 0.06 & 0.006 & 0.04 & 8.78 \\
\hline Case 2 & 0.04 & 0.04 & 0.03 & 0.03 & 0.02 & 0.02 & 0.02 & 0.02 & 0.02 & 5.25 \\
\hline Case 3 & 0.02 & 0.01 & 0.02 & 0.02 & 0.01 & 0.01 & 0.01 & 0.01 & 0.01 & 3.44 \\
\hline Case 4 & 0 & 0 & -0.01 & 0 & 0 & 0 & -0.01 & 0 & 0 & 0.34 \\
\hline
\end{tabular}

The soil temperature increases of the four cases followed a descending sequence of case $1>$ case $2>$ case $3>$ case 4 . After 20 years of system operation, the soil temperature increases from case 1 to case 4 were $8.78^{\circ} \mathrm{C}, 5.25^{\circ} \mathrm{C}, 3.44^{\circ} \mathrm{C}$ and $0.34{ }^{\circ} \mathrm{C}$ respectively. Accordingly, all the four cases suffered from soil thermal imbalance, which was acceptable for case 4 , in terms of practical engineering.

In conclusion, the soil temperature almost remained unchanged when heat rejected to the soil and the extracted heat were basically balanced. At this time, GSHPS kept operating in a stable manner, 
with slightly fluctuated average soil temperatures and lower thermal imbalance ratios. Therefore, applying a heat recovery system in GSHPSs can reduce the soil imbalance ratio effectively, slow the increase of soil temperatures, and mitigate the problem of soil heat accumulation.

\section{Conclusions}

The transient simulation a model-based TRNSYS was chosen as the main research object. The soil temperature distributions of GSHPSs with different heat recovery ratios were investigated. A hotel building located in a summer-hot and winter-cold area was selected. Compared with conventional GSHPSs, heat recovery GSHPSs can effectively reduce ground thermal imbalances. The following conclusions can be drawn:

(1) GSHPSs with heat recovery maintained steady soil temperatures and thermal imbalance ratios over long-term use.

(2) The problem of soil thermal imbalance can be satisfactorily solved by applying a GSHPS with heat recovery, especially in hot-summer and cold-winter areas. In addition, a yearly thermal balance scheme of the GSHPS was established, given that the system constitution was conducive to fundamentally eliminating soil thermal imbalance.

(3) The thermal imbalance ratios of four cases, which were $44.3 \%, 35.6 \%, 28.1 \%$ and $8.0 \%$ respectively after 1-year of operation, reduced to $29.2 \%, 21.1 \%, 16.0 \%$ and $5.2 \%$ respectively after 20 years of operation. Furthermore, case 4 essentially demonstrated balanced heat extraction and rejection.

(4) Combining the data analyses in Sections 3.1 and 3.2, the soil temperatures of four cases all rose by $3.05{ }^{\circ} \mathrm{C}, 2.27{ }^{\circ} \mathrm{C}, 1.64{ }^{\circ} \mathrm{C}$ and $0.06{ }^{\circ} \mathrm{C}$ respectively, compared with initial temperatures. After 20 years, increases for the four cases were $8.78{ }^{\circ} \mathrm{C}, 5.25^{\circ} \mathrm{C}, 3.44^{\circ} \mathrm{C}$ and $0.34{ }^{\circ} \mathrm{C}$ respectively, revealing that the rise of soil temperatures decreased with increasing heat recovery ratios. All the four cases had a soil thermal imbalance, but that of case 4 was acceptable by practical engineering standards.

Author Contributions: All authors contributed to the paper. Zhongchao Zhao conceived the work and drafted the manuscript; Rendong Shen and Weixian Feng played an important role in model developing and results interpreting; Yong Zhang and Yanrui Zhang completed a part of the data analysis; All authors read and approved the final manuscript.

Funding: This research was funded by [Jiangsu marine and fishery science and technology innovation and extension project] grant number [HY2017-8] and [Zhenjiang funds for the key research and development project] grant number [GY2016002-1].

Acknowledgments: The authors gratefully acknowledge that this work was supported by Jiangsu marine and fishery science and technology innovation and extension project (HY2017-8) and Zhenjiang funds for the key research and development project (GY2016002-1).

Conflicts of Interest: The authors declare no conflict of interest.

\section{Nomenclature}

\begin{tabular}{|c|c|}
\hline COP & Coefficient of performance \\
\hline$Q_{\text {rejected }}$ & Heat rejected to the soil in summer $(\mathrm{kW})$ \\
\hline Capcooling & Cooling removed from the indoor enviroment $(\mathrm{kW})$ \\
\hline$P_{\text {cooling }}$ & Working consumed by the heat pump $(\mathrm{kW})$ \\
\hline$T_{\text {source, out }}$ & Outlet temperatures of circulating liquid in source side $\left({ }^{\circ} \mathrm{C}\right)$ \\
\hline$T_{\text {load,out }}$ & Outlet temperatures of circulating liquid in load side $\left({ }^{\circ} \mathrm{C}\right)$ \\
\hline$T_{\text {source, in }}$ & Inlet temperatures of circulating liquid in source side $\left({ }^{\circ} \mathrm{C}\right)$ \\
\hline$T_{\text {load, in }}$ & Inlet temperatures of circulating liquid in load side $\left({ }^{\circ} \mathrm{C}\right)$ \\
\hline$m_{\text {source }}$ & Mass flow rate of circulating liquid in heat pump source side $(\mathrm{kJ} /(\mathrm{kg} \cdot \mathrm{K}))$ \\
\hline$C p_{\text {source }}$ & Specific heat of circulating liquid in heat pump source side $(\mathrm{kJ} /(\mathrm{kg} \cdot \mathrm{K}))$ \\
\hline$m_{\text {load }}$ & Mass flow rate of circulating liquid in heat pump load side $(\mathrm{kJ} /(\mathrm{kg} \cdot \mathrm{K}))$ \\
\hline$C p_{\text {load }}$ & Specific heat of circulating liquid in heat pump loading side $(\mathrm{kJ} /(\mathrm{kg} \cdot \mathrm{K}))$ \\
\hline
\end{tabular}




$\begin{array}{ll}Q_{i} & \text { Hourly heating or cooling load, } \mathrm{kW} \\ Q_{A H L} & \text { The accumulated heating load, } \mathrm{kW} \\ Q_{A C L} & \text { The accumulated cooling load, } \mathrm{kW} \\ Q_{A H E} & \text { The accumulated heating extraction during heating period, } \mathrm{kW} \\ Q_{A C R} & \text { The accumulated heating rejection during cooling period, } \mathrm{kW} \\ C O P_{\text {heating }} & \text { The hourly heating COP } \\ C O P_{\text {cooling }} & \text { The hourly cooling COP } \\ \text { IR } & \text { Thermal imbalance ratio }\end{array}$

\section{References}

1. Stuart, J.S.; Bale, V.R.; Marc, A.R. Geothermal heat pump systems: Status review and comparison with other heating options. Appl. Energy 2013, 101, 341-348. [CrossRef]

2. You, T.; Wu, W.; Shi, W.X.; Wang, B.L.; Li, X.T. An overview of the problems and solutions of soil thermal imbalance of ground-coupled heat pumps in cold regions. Appl. Energy 2016, 177, 515-536. [CrossRef]

3. Li, W.D.; Li, X.D.; Wang, Y.; Tu, J.Y. An integrated predictive model of the long-term performance of ground source heat pump (GSHP) systems. Energy Build. 2018, 159, 309-318. [CrossRef]

4. Jiang, H.Y. System Performance Investigation and Optimization Retrofit of an Existing Ground Source Heat Pump System in the Severe Cold Zone of China. Master's Thesis, Shandong Jianzhu University, Shandong, China, 13 June 2016.

5. Che, W.H.; Bai, L.; Hua, Y.W.; Chang, W.T.; Chu, T.M. The Contribution of ground source heat pump to reduce the haze weather. J. Jilin Jianzhu Univ. 2015, 32, 43-45.

6. Sarbu, I.; Sebarchievici, C. General review of ground-source heat pump systems for heating and cooling of buildings. Energy Build. 2014, 70, 441-454. [CrossRef]

7. Spitler, J.; Bernier, M. Ground-source heat pump systems: The first century and beyond. HVAC R Res. 2011, 17, 891-894. [CrossRef]

8. Aikens, K.A.; Choi, J.M. Current status of the performance of GSHP (ground source heat pump) units in the Republic of Korea. Energy 2012, 47, 77-82. [CrossRef]

9. Bayer, P.; Saner, D.; Belay, S.; Rybach, L.; Blum, P. Greenhouse gas emission savings of ground source heat pump systems in Europe: A review. Renew. Sustain. Energy Rev. 2012, 16, 1256-1267. [CrossRef]

10. Qian, H.; Wang, Y. Modeling the interactions between the performance of ground source heat pumps and soil temperature variations. Energy Sustain. Dev. 2014, 23, 115-121. [CrossRef]

11. Ji, W.J.; You, T.; Bai, S.W. Effects of buried pipe design parameters on performance of ground-source heat pump systems in cold zone. Heat. Vent. Air Cond. 2015, 45, 113-118.

12. Ruiz-Calvo, F.; Cervera-Vázquez, J.; Montagud, C.; Corberán, J.M. Reference data sets for validating and analyzing GSHP system based on an eleven-year operation period. Geothermics 2016, 64, 538-550. [CrossRef]

13. Zhu, N.; Hu, P.F.; Xu, L.H.; Jiang, Z.G.; Lei, F. Recent research and applications of ground source heat pump integrated with thermal energy storage systems: A review. Appl. Therm. Eng. 2014, 71, 142-151. [CrossRef]

14. Nguyen, H.V.; Law, Y.L.E.; Alavy, M.; Walsh, P.R.; Leong, W.H.; Dworkin, S.B. An analysis of the factors affecting hybrid ground-source heat pump installation potential in North America. Appl. Energy 2014, 125, 28-38. [CrossRef]

15. Rad, F.M.; Fung, A.S.; Leong, W.H. Feasibility of combined solar thermal and ground source heat pump systems in cold climate, Canada. Energy Build. 2013, 61, 224-232. [CrossRef]

16. Hu, P.F.; Hu, Q.S.; Lin, Y.L.; Yang, W.; Xing, L. Energy and exergy analysis of a ground source heat pump system for a public building in Wuhan, China under different control strategies. Energy Build. 2017, 152, 301-312. [CrossRef]

17. Xia, L.; Ma, Z.J.; McLauchlan, C.; Wang, S. Experimental investigation and control optimization of a ground source heat pump system. Appl. Therm. Eng. 2017, 127, 70-80. [CrossRef]

18. Yang, W.; Sun, L.; Chen, Y. Experimental investigations of the performance of a solar-ground source heat pump system operated in heating modes. Energy Build. 2015, 89, 97-111. [CrossRef]

19. You, T.; Shi, W.X.; Wang, B.L.; Wu, W.; Li, X.T. A new ground-coupled heat pump system integrated with a multi-mode air-source heat compensator to eliminate thermal imbalance in cold regions. Energy Build. 2015, 107, 103-112. [CrossRef] 
20. Schibuola, L.; Tambani, C.; Zarrella, A.; Scarpa, M. Ground source heat pump performance in case of high humidity soil and yearly balanced heat transfer. Energy Convers. Manag. 2013, 76, 956-970. [CrossRef]

21. Liu, X.R. Analysis of heat balance and regional characteristics of ground-coupled heat pump systems. Heat. Vent. Air Cond. 2008, 38, 57-59. [CrossRef] 